\title{
Ideologia de gênero, religião e a política dos corpos: A disputa contemporânea pelo controle dos sentidos culturais
}

\author{
Gender ideology, religion and the politics of bodies: The contemporary dispute for the control of \\ cultural senses \\ Ideología de género, religión y política de los cuerpos: La disputa contemporánea por el control de \\ los sentidos culturales
}

Recebido: 19/11/2021 | Revisado: 27/11/2021 | Aceito: 30/11/2021 | Publicado: 12/12/2021

Aparecido Francisco dos Reis ORCID: https://orcid.org/0000-0003-1389-4317 Universidade Federal de Mato Grosso do Sul, Brasil E-mail: aparecido.reis@ufms.br

\begin{abstract}
Resumo
O tema subjacente a este artigo trata da disputa contemporânea por significados culturais, ou o que outros chamam de guerra cultural, sobre os direitos sexuais e reprodutivos das mulheres e as sexualidades dissidentes LGBTQIA+ a partir do debate em torno ao tema de gênero e/ou ideologia de gênero, assim nomeado por grupos religiosos conservadores. O artigo parte das análises de documentos papais e do episcopado brasileiro, das conferências internacionais da ONU sobre mulheres e de tensões recentes sobre o assunto na sociedade brasileira. Os resultados demonstram que esse crescente confronto em torno da escolha da questão que envolve os direitos sobre os corpos de mulheres e de dissidências sexuais ocorre dentro do contexto histórico-estrutural de transição de épocas. A mudança da modernidade industrial para os tempos pós-industriais questionou aspectos elementares da modernidade como: a definição de pessoalidade; a noção de cidadania; os limites entre o público e o privado; a relação entre igreja e estado e a natureza do projeto nacional. Desse modo, o artigo identifica a complexidade do tema a partir da análise da posição da hierarquia católica e contextualiza o momento histórico e estrutural em que a disputa se intensifica, sobretudo no caso brasileiro.
\end{abstract}

Palavras-chave: Sexualidade; Narrativas; Direitos sexuais e reprodutivos; Ideologia de gênero.

\begin{abstract}
The underlying theme of this article deals with the contemporary dispute for cultural meanings, or what others call cultural war, on women's sexual and reproductive rights and LGBTQIA+ dissenting sexualities from the debate around the theme of gender and/or ideology named by conservative religious groups. The article starts from the analysis of papal documents and the Brazilian episcopate, from the UN international conferences on women and from recent tensions on the subject in Brazilian society. The results demonstrate that this growing confrontation over the choice of the issue involving rights over women's bodies and sexual dissidences takes place within the historicalstructural context of the transition of epochs. The shift from industrial modernity to post-industrial times challenged elementary aspects of modernity such as: the definition of personhood; the notion of citizenship; the boundaries between public and private; the relationship between church and state and the nature of the national project. In this way, the article identifies the complexity of the theme from the analysis of the position of the Catholic hierarchy and contextualizes the historical and structural moment in which the dispute intensifies, especially in the Brazilian case.

Keywords: Sexuality; Narratives; Sexual and reproductive rights; Gender ideology.
\end{abstract}

\section{Resumen}

El tema subyacente de este artículo trata sobre la disputa contemporánea por significados culturales, o lo que otros llaman guerra cultural, sobre los derechos sexuales y reproductivos de las mujeres y las sexualidades disidentes LGBTQIA + del debate en torno al tema de género y / o ideología mencionado por grupos religiosos conservadores. El artículo parte del análisis de los documentos papales y del episcopado brasileño, de las conferencias internacionales de la ONU sobre la mujer y de las tensiones recientes sobre el tema en la sociedad brasileña. Los resultados demuestran que este creciente enfrentamiento por la elección del tema de los derechos sobre el cuerpo de las mujeres y las disidencias sexuales se da en el contexto histórico-estructural de la transición de épocas. El paso de la modernidad industrial a los tiempos postindustriales puso en tela de juicio aspectos elementales de la modernidad como: la definición de persona; la noción de ciudadanía; los límites entre lo público y lo privado; la relación entre la iglesia y el estado y la naturaleza del proyecto nacional. De esta manera, el artículo identifica la complejidad del tema 
a partir del análisis de la posición de la jerarquía católica y contextualiza el momento histórico y estructural en el que se agudiza la disputa, especialmente en el caso brasileño.

Palabras clave: Sexualidad; Narrativas; Derechos sexuales y reproductivos; Ideología de género.

\section{Introdução}

O tema deste artigo versa sobre as controvérsias e disputas em torno aos significados culturais na época atual, tendo como objetivo a problemática envolvendo a sexualidade e os direitos sexuais e reprodutivos, enquanto centralidade de uma política dos corpos, vista em duas perspectivas: uma da ordem sagrada e natural, outra, da ordem construída historicamente. Assim, é possível perceber o enfrentamento dessas disputas que, inclusive, se organizam em lutas institucionais, perpassando a esfera do Estado nacional enquanto comunidade imaginada e detentor dos poderes legais sobre a sociedade.

$\mathrm{Na}$ pauta atual, os direitos reprodutivos e sexuais, os corpos de mulheres e LGBTQIA+ (Lésbicas, Gays, Bissexuais, Travestis, Transexuais, Queer, Intersexuais, Assexuais e outros) têm sido fonte de dissensos que mobilizam a opinião pública no Brasil e em outras partes do Ocidente. No Brasil, em 2017 houve ampla mobilização dos movimentos de mulheres e feministas contra o Projeto de Emenda Constitucional (PEC) 181/2015, que propõe inserir na Constituição Federal a proteção à vida desde a concepção, tornando embriões e fetos sujeitos de direitos, transformando em ilegais os casos de aborto previstos em lei (casos de estupro, risco de vida para a mulher e de feto anencéfalo). Essa proposta é encabeçada pela bancada de deputados Pró vida e Pró família, criada em 2006 e que vem pressionando a aprovação de projetos que restringem direitos reprodutivos ${ }^{1}$.

Os grupos religiosos tem como alvo principal as questões de gênero e a diversidade sexual a partir de um discurso organizado em torno de uma visão essencialista da identidade de gênero e da sexualidade, fazem uma oposição sistemática à criminalização da homofobia; à despenalização do aborto, assim como fazem campanha e projetos legislativos que visam restaurar uma moral social fundada numa ordem natural e sagrada. Projetos como da "cura gay", (Projeto de Lei 4931 de 2016) e a PEC 181/15 já mencionada, que proíbe e criminaliza todo e qualquer tipo de aborto, são exemplos dessa contenda. Há ainda o embate em torno da discussão de gênero ou ideologia de gênero e orientação sexual na educação, que tem influenciado parlamentares a apresentarem projetos em diferentes níveis de governo (municipal, estadual e federal) proibindo que o assunto seja discutido nos livros didáticos e por professores.

Embora seja recorrente em diferentes denominações religiosas, neste artigo, o tema será discutido apenas a partir das orientações da hierarquia católica sobre o assunto em contraponto à visão de mundo dessencializadora da identidade de gênero, dos direitos sexuais e reprodutivos e da sexualidade.

\section{Metodologia}

a metodologia utilizada contextualiza o problema a ser analisado por meio da apresentação da narrativa das lideranças da Igreja Católica e sua representação da categoria de gênero e dos direitos reprodutivos e sexuais como uma essencialidade que reproduz a ordem divina e biológica. Assim, serão pensados os discursos e documentos dos papas Bento XVI e Francisco e a posição dos bispos brasileiros, por meio de notas da Conferência Nacional dos Bispos do Brasil (CNBB) e uma nota da Conferência Episcopal do Peru, que criou o termo ideologia de gênero. Essa narrativa reforça ainda que feministas e militantes LGBTQIA+ utilizam da categoria gênero como uma ideologia, que ameaça a continuidade da instituição familiar e da sociedade.

\footnotetext{
${ }^{1}$ Segundo o Jornal O Estado de Minas, em 2020 essa bancada contava com 311 deputados\#, sendo 54\% deles católicos e 46\% evangélicos: https://www.em.com.br/app/noticia/politica/2020/01/28/interna_politica,1117561/parlamentares-catolicos-planejam-frente-conjunta-comevangelicos.shtml .
} 
A articulação e análise dessa narrativa será feita a partir de dois eixos teóricos principais: dos autores que pensam as transformações referentes ao mundo atual como o colapso do projeto moderno de civilização e da sociedade industrial capitalista e liberal, incapaz de responder completamente às demandas sociais subjacentes ao modelo que foi implantado nos séculos anteriores ao atual, e; dos autores e autoras que fazem a reflexão acerca dos sujeitos sociais no bojo dessas transformações, em sua busca por reconhecimento de novas cidadanias com base numa visão histórica e cultural das relações de gênero, do corpo e das sexualidades.

Por fim, alerta-se que o material utilizado, ou seja, os discursos papais e as notas da CNBB não possuem paginação, sendo consultadas a partir dos sites oficiais do Vaticano, da CNBB e de movimentos católicos. Foram ainda consultadas e coletadas informações na plataforma de vídeos Youtube, em portais de jornais e em sites diversos.

\section{Articulando o Problema: Discussão e Resultados}

A sexualidade, o aborto, a igualdade de gênero e a política dos corpos são temas contemporâneos com forte apelo emocional que tem suscitado tensos debates tanto, interno como externamente ao Brasil, sobretudo nas redes sociais. Particularmente, o Brasil enfrenta atualmente um debate público sobre as margens de autonomia reprodutiva das mulheres ou ainda; sobre o direito das populações LGBTQIA+ de se casarem e adotarem crianças, de constituírem famílias, de realizarem o processo transexualizador e do uso de nome social por pessoas trans. Há ainda toda uma discussão política sobre as questões de gênero na educação.

Nas duas primeiras décadas do século XXI, esse debate público tem influenciado eleições, estabelecido uma nova agenda política e alguns acontecimentos têm sido importantes na identificação dessa problemática. Já nas eleições de 2010, os presidenciáveis Dilma Roussef e José Serra tiveram que assinar uma carta de intenções com setores religiosos conservadores, assumindo o compromisso que não iriam pautar nenhum projeto que pudesse legalizar o casamento entre pessoas do mesmo sexo, a descriminilização do aborto e das drogas, ou ainda, a abordagem a questão de gênero, nomeada por esses segmentos, como ideologia de gênero.

Nesse sentido, grupos religiosos têm feito lobby sobre parlamentares das diversas instâncias legislativas, que vem criando leis com a finalidade de proibir e até punir, escolas e professores que tratem dessa questão em sala de aula. Articulados em torno do catolicismo e outras denominações cristãs, os religiosos condenam o que denominam "a perniciosa ideologia de gênero"2, como vimos nos debates sobre o Plano Nacional de Educação em nosso país durante a última década.

Para Rosado, a força de desconstrução do gênero pode ser, de fato, assustadora para a sociedade, mas de modo especial para as religiões do campo cristão essa força parece mais ameaçadora ao deslocar os temas da identidade de gênero e da sexualidade, da natureza para a história, pondo em dúvida a existência de uma ordem natural e sagrada sobre a produção dos corpos. Os séculos de hegemonia da religião, sobretudo do catolicismo no Brasil, permitiram a construção de uma compreensão do sexo como:

Vinculado à reprodução e a absolutização da heteronormatividade. Era possível assim à Igreja Católica influir fortemente sobre os princípios de regulação social da sexualidade, atuando sobre o Estado e fundando uma moral sexual a ser seguida por toda a população. (Rosado, 2018, p. 18).

No Brasil, a expressão ideologia de gênero tornou-se uma forma eficaz de marcar e desqualificar ativismos que buscam transformar o gênero e as hierarquias sexuais que definem a masculinidade e a heterossexualidade como referentes privilegiados na construção do mundo. O termo, segundo Rosado (2018), refere-se a uma estratégia do ativismo católico

\footnotetext{
${ }^{2}$ https://www.ofielcatolico.com.br/2005/05/a-perniciosa-ideologia-de-genero.html.
} 
conservador para contrariar, por meio da formação de cidadãos crentes, a politização do prazer e a configuração das cidadanias sexuais feitas por feministas e ativistas pela diversidade sexual nas últimas décadas. Junto com sua contraparte, a cultura da morte, constitui a ponta de lança de estratégias conservadoras para revitalizar a debilitada hegemonia da Igreja Católica em relação ao monopólio religioso, moral e legal da sexualidade.

O estudo de Mariano (2013) aponta para o aumento da diversidade no cenário religioso brasileiro, principalmente após a reconstrução democrática do final do século XX; ao avanço da globalização dos discursos sobre direitos e liberdades, bem como as transformações da modernidade secularizada foram acompanhadas pelo surgimento de novos movimentos religiosos, principalmente de grupos neopentecostais evangélicos, marcando o declínio da influência da Igreja Católica no país. Segundo Mariano, esses grupos têm se aglutinado em torno de uma religião de cunho mais afetivo e emocional e defensores de valores considerados conservadores (pró vida e pró família) (Mariano, 2013, pp. 119-120).

No entanto, segundo Vaggione (2017) foram os avanços do feminismo e dos movimentos por diversidade sexual em escala internacional a partir de meados da década de 1980, que questionaram seriamente a regulação sexual enquanto discurso da Igreja Católica:

Estos movimientos politizan, vuelven visibles, la influencia de la moral católica en la construcción de las dimensiones culturales de la ciudadanía. La demanda por derechos vinculados a la sexualidad interrumpe (al menos parcialmente) esta ficción evidenciando la forma en que la moral sexual católica se universaliza bajo el ropaje del ciudadano. (Vaggione, 2017, n. p.)

Segundo Junqueira (2017), o termo ideologia de gênero refere-se aos "processos de naturalização das relações de gênero, a subordinação das mulheres, a assimetria de poder e de acesso aos recursos por parte das mulheres em relação aos homens". (Junqueira, 2017, p. 48)

Souza Junior (2019) aponta que o termo é uma invenção católica que emergiu a partir do conjunto doutrinário do Conselho Pontifício para a Família e da Congregação para a Doutrina da Fé, entre meados da década de 1990 e no início dos 2000. "Trata-se de um sintagma urdido no âmbito da formulação de uma retórica reacionária antifeminista, sintonizada com o pensamento e o catecismo de Karol Wojtyla”. (Souza Junior, 2019, p. 57).

Mas, a identificação do termo gênero como uma ideologia, pode ser encontrada pela primeira vez, em nota da Conferência Episcopal Peruana publicada em abril de 1998 sob o título: "La Ideología de Género. Sus Peligros y Alcances"3. No texto da nota, os bispos alertam que muitas pessoas talvez por falta de informação, ainda não conhecem a nova proposta e as suas perigosas implicações. Segundo os mesmos, essa ideologia estaria já, naquele momento, ganhando força nos países desenvolvidos, sobretudo nas universidades dos Estados Unidos, mas também aparentemente teria começado a se infiltrar nos países latinoamericanos, através dos materiais didáticos difundidos não só nas escolas, mas também em universidades de prestígio.

Apesar do termo ter sido uma invenção dos hierárquicas católicos com base em um pensamento neofundamentalista vigente no papado de João Paulo II, no Brasil, o termo foi amplamente aceito pelas Igrejas Neopentecostais e outros movimentos conservadores da sociedade civil como o Escola Sem Partido ${ }^{4}$, tendo por objetivos a defesa de valores ligados à família tradicional, aos papéis essencializadores do homem e da mulher e a uma pretensa neutralidade política nos livros didáticos e no ensinamento dos professores.

${ }^{3}$ https://www.aciprensa.com/controversias/genero.htm?fbclid=IwAR1ikZsBLZnMuz-0kgukAD_Lx9Vzo47F70fwOeNPOJo8MsTnRDYt1oRv6Y.

${ }^{4}$ https://www.escolasempartido.org/ 
Nesse sentido, como objeto, a ideologia de gênero está inscrita em fluxos discursivos e redes de ativismo conservador em escala global e continental que se articulam com lógicas nacionais específicas. Por isso, mais do que um objeto “importado" pelos religiosos para o Brasil com o obejtivo de defender o lugar da religião na modernidade, a ideologia de gênero é produzida em diferentes lugares, apropriada por agentes religiosos e não religiosos e mobilizada em meios aparentemente alheios aos direitos das mulheres, lésbicas, gays, bissexuais e transgêneros.

A ideologia de gênero é um objeto difícil de definir, pois seu significado é vago. E embora aluda à lutas e agentes particulares, sua referência é aberta, por isso está pronta para ser esvaziada e preenchida de acordo com o contexto de sua implantação, e nela reside muito de sua eficácia. Portanto, é mais útil defini-la de acordo com o fim almejado.

Percebe-se que o termo ideologia de gênero envolve uma prática de nomeação. Refere-se a um outro ao qual delimita incessantemente. No Brasil, tem sido usado para nomear indivíduos e instituições, por exemplo, professores, intelectuais, universidades públicas, Ministros do Supremo Tribunal Federal, juízes, líderes políticos e organizações sociais, e até mesmo entidades internacionais, como a Comissão Interamericana de Direitos Humanos e agências do sistema das Nações Unidas. Quando enunciada, a ideologia de gênero estabelece relações de vizinhança entre agentes definidos como ameaças a uma ordem natural e sagrada, muitas vezes simbolizada pela figura das crianças. O lugar indesejável que ela constitui é paradoxalmente reforçado por aqueles que, quando nomeados, buscam se dissociar da ideologia de gênero.

Dada a natureza aberta e expansiva de sua fronteira, ninguém é excluído de ser nomeado como um ideólogo de gênero. Classificar agentes tão díspares como ideólogos de gênero é possível por não diferenciá-los parcial ou totalmente, tornando todos igualmente equivalentes. Nesse sentido, a ideologia de gênero pode ser entendida como um vazio significativo.

Segundo Laclau (2013) no campo das lutas políticas, agentes com objetivos políticos diferenciados e/ou opositores de um regime repressivo são muitas vezes percebidos como equivalentes em virtude de seu antagonismo confluente à frente do sistema. Consequentemente, a "comunidade" que eles compõem como antagonistas é o produto da "renúncia de sua identidade diferencial" em favor de sua associação de equivalência, ou seja, o esvaziamento do significado dos elementos articulados (Laclau, 2013, 78).

No entanto, a lógica de equivalência é um processo inacabado. É uma tendência simultaneamente contrariada por uma lógica diferencial, uma vez que para que a comunidade seja representada deve ter "alguma identidade constituída dentro do espaço equivalência" (Laclau, 2013, p.80). Essa escolha, depende do momento histórico, que dá maior ou menor relevância aos agentes articulados.

Ambas as lógicas estão presentes na definição de ideologia de gênero, embora, neste caso, agentes relacionados não incorporem a comunidade, mas seu outro. No Brasil, os governos do PT em todas as instâncias foram duramente criticados por defender uma agenda considerada promotora da ideologia de gênero por meio do programa Brasil Sem Homofobia ${ }^{5}$, kit gay ${ }^{6}$, autorização para realização do processo transexualizador no sistema público de saúde ${ }^{7}$ e outros benefícios concedidos às pessoas transexuais, como o direito ao uso do nome social ${ }^{8}$. Além disso, em 2013 o Conselho Nacional de Justiça obrigou todos os cartórios do território nacional a oficializar o casamento entre pessoas do mesmo gênero 9 .

\footnotetext{
${ }^{5}$ Ministério da Saúde/Conselho Nacional de Combate à Discriminação, 2004,

${ }^{6} \mathrm{O}$ suposto kit era material educativo composto de vídeos, boletins e cartilhas com abordagem do universo de adolescentes homossexuais que seria distribuído para seis mil escolas da rede pública no programa Mais Educação. A produção e a distribuição desse material foi proibida por ordem da Presidente Dilma Rousseff em 2011, por pressão da bancada religiosa no Congresso Nacional, mas segundo decisão do Tribunal Superior Eleitoral em 16/10/2018 o kit nunca existiu. A decisão proibiu Bolsonaro de divulgar notícias falsas sobre o material.

${ }^{7}$ Portaria n. ${ }^{\circ} 1.707$ do Ministério da Saúde

${ }^{8}$ Decreto 8.727 de 28/04/2016 - da Presidente Dilma Rousseff

${ }^{9}$ Resolução 175/2013 do Conselho Nacional de Justiça
} 
Assim, o ativismo contra ao que se chama ideologia de gênero tem feito equivalentes em seu discurso: ateus, comunistas, homossexuais, feministas, corruptos, imorais e outros grupos, são recorrentemente nomeados como os inimigos da nação, da família, da religião e do Estado. No imaginário coletivo dos religiosos conservadores, a referência associada às ideologias de gênero tem oscilado entre o "lobby gay", "abortistas" e "comunistas", segundo o contexto.

Nessa visão de mundo, a ideologia de gênero define um lugar de excesso. Na história da metafísica cristã e da filosofia moderna, o excesso tem sido ligado à transgressão e ao pecado. No pensamento ocidental, sua expressão tem sido a de fúria, loucura, barbárie e ausência de domínio de si mesmo. Segundo Dumoulié (2007), na política, o excesso encarna a tirania e o "terror revolucionário" (Dumoulié, 2007, pp. 263, 265 e 272).

Nesse contexto, a ideologia de gênero caracteriza-se por sua inflação. Seus promotores formam uma extensa família de ascendência política e intelectual heterogênea, mas perigosa na visão doutrinária católica. O teólogo moral Pedro Trevijano, afirma que o caráter dos criadores e defensores da ideologia de gênero evidencia-se por uma vida marcada pelos excessos e pela imoralidade. Filósofos como Nietzsche, Foucault e Althusser, sexólogos como Kinsey, escritores como Bataille, feministas como Firestone, Millet e defensores do planejamento familiar como Margaret Sanger foram marcados pela loucura, vício em drogas, suicídio, satanismo, comunismo e homossexualidade. Todos esses pensadores e pesquisadores eram tiranos e revolucionários à sua maneira. O excesso define suas práticas e pensamentos. (Trevijano, 2018, pp. 11-12)

O Cardeal Joseph Ratzinger, ainda como Prefeito da Sagrada Congregação para a Doutrina da Fé, em Carta dirigida aos bispos católicos sobre a colaboração do homem e da mulher na Igreja e no mundo (2004), o excesso é identificado como uma forma de insurreição contra a ordem natural e sagrada ao pontuar que na época atual há duas tendências discursivas predominantes no tema da mulher. Segundo ele, a primeira tendência, ao falar da subordinação ao homem, apontando que para a mulher livre, deve-se colocar em posição antagônica ao homem, "o seu revés mais imediato e nefasto na estrutura da família". (Ratzinger, 2004, n.p.). A segunda tendência no entendimento do cardeal, deriva da primeira e estabelece que todo e qualquer movimento sobre a libertação das mulheres serve como um centro nuclear para qualquer atividade libertária, tanto política quanto antropológica, com o objetivo de fazer o ser humano livre de sua biologia. O fenômeno biológico da sexualidade é então distinguido de suas formas históricas e culturais, que são chamadas de gênero, mas a chamada revolução contra formas históricas de sexualidade culmina em uma revolução contra pressupostos biológicos. Não é mais admitido que "natureza" tem nada a dizer, é melhor que o homem possa se modelar ao seu gosto, ele tem que se libertar de qualquer pressuposto de seu ser: o ser humano tem que se fazer de acordo com o seu desejo, só dessa forma ele será "livre". Para Ratzinger, essa ideia apenas disfarça uma insurreição do homem contra os limites que ele carrega enquanto ser biológico. É contra, no último extremo, ser uma criatura, não se aceitando como criatura, se transformando em seu próprio criador, uma versão moderna desse "vocês serão como deuses: ele tem que ser como Deus". (Ratzinger, 2004, n. p.).

Como Papa Bento XVI, retornou ao assunto da defesa da ordem natural e sagrada na Encíclica Deus Caritas Est de 2005, afirmando em um trecho que “(...) encontramo-nos diante duma degradação do corpo humano, que deixa de estar integrado no conjunto da liberdade da nossa existência,deixa de ser expressão viva da totalidade do nosso ser, acabando como que relegado para o campo puramente biológico" (BENTO XVI, 2005, n. p.). O Papa qualifica ainda as relações entre pessoas do mesmo sexo como "amor fraco", uma vez que este não frutifica em termos de trazer novas vidas ao mundo. Somente o amor heterossexual é considerado "forte", enquanto o amor homossexual seria hedonista e egoísta.

Anos mais tarde, em carta de Natal endereçada à Cúria Romana (2012), ele mencionou que o diálogo entre as religiões deve abordar problemas específicos que afetam a convivência social, o Estado e a humanidade, sendo o mais premente: "uma nova filosofia de sexualidade", definida em torno do gênero, que ameaça a concepção do próprio homem. Citando Gilles Bernheim, um rabino da França, Bento XVI afirmou que o núcleo conceitual dessa filosofia foi encontrado na 
frase da feminista Simone de Beauvoir "mulher não nasce, é feita"10, da qual é colidido que é a sociedade, e não Deus, que define a natureza humana. Para o Papa Emérito, essa autonomia extrema, na qual o homem é um feitor de si mesmo, desconsidera sua "demanda criacional" eliminando a ordem sagrada e natural. Para ele, isso constitui uma "revolução antropológica". A correlação disso seria "a prole", que deixou de obedecer ao direito natural para se tornar o objeto de um direito contestado por diferentes grupos sociais.

O uso de categorias (revolução, insurreição) que aludem à desestabilização ou ruptura de uma ordem política como uma ordem sagrada e natural é significativo, pois define as lutas feministas como "poder destrutivo" dirigidas contra Deus, natureza e identidade humana.

O excesso de liberdade e autonomia que feministas e ativistas LGBTQIA+ teriam buscado, assume a forma de colonização para o Papa Francisco. Em sua turnê pelo Sri Lanka e pelas Filipinas em 2015, Francisco dirigiu-se publicamente às famílias em um evento realizado em Manila. Lá, ele pediu aos seus ouvintes que ficassem "atentos às novas colonizações ideológicas [...] buscando destruir a família impondo um estilo de vida "materialista" (Francisco, 2015, n. p.). Ele comparou essa ameaça à invasão de potências estrangeiras às Filipinas e pediu ao seu público que tivesse a "maturidade" para rejeitar toda a colonização ideológica como havia feito com a colonização política. (2015). Em julho de 2016, dirigindo-se aos bispos poloneses, Francisco reforça o alerta acerca das colonizações ideológicas ${ }^{11}$ :

Na Europa, na América, na América Latina, na África, em alguns países da Ásia, há verdadeiras colonizações ideológicas. E uma destas, digo claramente com nome e sobrenome - é a ideologia de gênero! Hoje ensinam as crianças - as crianças! -, que estão na escola: que cada um pode escolher o seu sexo. E por que ensinam isto? Porque os livros são das pessoas e instituições que lhes dão dinheiro. São as colonizações ideológicas, sustentadas também por países muito influentes. Isto é terrível. (Apud Battisti, 2017, n. p.)

Para explicar a que se referia, em uma coletiva de imprensa ainda em 2016 durante a Jornada Mundial da Juventude em Cracóvia, Polônia, o papa lembrou um episódio ocorrido na Argentina quando ainda era cardeal de Buenos Aires. Segundo ele, a ministra da Educação conseguiu um empréstimo para construir escolas para os pobres, mas os credores teriam exigido que ela incluísse no currículo "um livro escolar, um livro bem preparado didaticamente, ensinando ideologia de gênero". Ele argumentou que esse material fazia parte de uma estratégia de colonização ideológica, uma vez que trazia ideias estrangeiras para um povo com o propósito de mudar sua mentalidade. Ele então comparou os esforços para transformar as desigualdades de gênero na escola com propaganda nazista e de meados do século XX voltada para crianças e jovens: "Mas isso não é novo. Assim como as ditaduras do século passado. Eles vieram com sua doutrina. Lembre-se, a Juventude Hitlerista colonizou o povo" $(2016)^{12}$.

A ideologia de gênero é representada, nesses discursos, não apenas como um excesso, mas também como um perigo para a religião e para "o povo". E assim, enquanto envolve formas de conceber a família, o papel dos homens e das mulheres na sociedade e as formas aceitas de gerenciar o desejo, ela sobrecarrega o gênero e a sexualidade, pois está propondo também projetos de nação e cidadania, o que lhe dá especial relevância política.

Para a Conferência Nacional dos Bispos do Brasil (CNBB), em nota de 2010², explica que existem diferenças entre o feminismo legítimo em contraponto ao um feminismo delirante:

\footnotetext{
${ }^{10} \mathrm{https} / / / \mathrm{www} . v a t i c a n . v a / c o n t e n t /$ benedict-xvi/pt/speeches/2012/december/documents/hf_ben-xvi_spe_20121221_auguri-curia.html.. ${ }^{11} \mathrm{https}: / /$ www.cnbb.org.br/ideologia-de-genero/.

${ }^{12} \mathrm{https} / / /$ operariosdamesse.org.br/blogs/artigos/674-atualidadeideologia-de-generopais-e-filhos-o-que-pensa-o-papa-francisco-sobre-aideologia-de-genero.html.

${ }^{13}$ https://www.cnbb.org.br/elas-deverao-aprender-de-novo/.
} 
O feminismo legítimo conquistou espaços impossíveis de prever antes de Cristo, como direito ao voto, a exercer profissões, e ter voz ativa no mundo. As mulheres, por serem muito intuitivas, sabem que o cristianismo lhes garantiu ares novos. As mais esclarecidas são agradecidas ao Bom Mestre que, contrariamente a todas as pessoas famosas, nunca fez campanha contra elas, nem as colocou em situação infamante ou de desdém. (CNBB, 2021, n. p)

As feministas legítimas, esclarece, lutam para melhorar as condições de vida das mulheres, garantir-lhes melhores salários e tratamento igualitário, enquanto algumas mulheres da "vertente poluída", sem paz, agressiva e sem fé buscam nenhuma distinção dos sexos e destroem a identificação dos interesses das mulheres com os de suas famílias:

Sim, em vez de querer ser esposa, o plano agora é ser amante sem compromisso. Sua glória não é mais ser mãe, mas praticar a greve do seio. Em vez de ser depositária da vida, manifesta-se favorável ao aborto. A educação monótona dos filhos é entregue a outras pessoas. (CNBB, 2021, n. p.)

Então, desde 2010, até o ano de 2021, a CNBB, publicou 19 notas sobre o tema, sempre reforçando que a igreja não se opõe ao feminismo em geral e ao respeito à dignidade de pessoas LGBTQIA+, mas se posiciona sempre contra os movimentos que negam a correlação entre sexo como verdade biológica e o gênero. Para os bispos, a ideologia de gênero aparece, portanto, como um excesso do feminismo, de intelectuais e de militantes mais radicais, mas não dos que buscam a igualdade e o respeito. Em nota publicada em 2021, a CNBB entende que o excesso se expressa no caráter fanático das ideologias com as quais é impossível estabelecer um diálogo; e que, em vez de celebrar as conquistas da igualdade entre homens e mulheres, acusam aqueles que o fazem de serem alienados. Para a hierarquia católica, o único interesse dessa vertente, assim chamada de "poluída" é dizer que "não há nem homens nem mulheres", para "desconstruir tudo". São as "feministas de gênero"14.

Invocando a ideologia de gênero, esse ativismo conservador acentua antagonismos entre feministas e ativistas LGBTQIA+, por um lado, e os crentes cidadãos, por outro. Também faz uma distinção entre feministas boas e más: aqueles que buscam equidade e as insurgentes que violam a própria condição do ser humano como um ser divino e criatura biológica. Consistentemente, a ideologia de gênero, como prática de nomeação, não apenas desqualifica, também produz formas aceitáveis e "democráticas" de fazer reivindicações sobre a equidade entre homens e mulheres. -Ao mesmo tempo, a igreja rejeita o excesso de ideologias de gênero, levantando assim uma abertura ao feminismo, mas que saiba articular suas demandas sem questionar a diferença sexual como um fato da natureza. Nesse sentido, a ideologia de gênero tem um potencial normalizador.

Há ainda uma ofensiva religiosa contra o direito ao aborto legal e seguro. O caso ocorrido em 2020 de uma menina do estado do Espírito Santo, de apenas 10 anos de idade, com gravidez resultante de estupros causados pelo tio, obteve permissão judicial para fazer o aborto num hospital público. A justiça, no entanto, encaminhou a menina para realizar o procedimento na cidade do Recife, no estado de Pernambuco. A decisão judicial gerou protestos e reações que chegaram à vítima na forma de insultos, por parte dos grupos católicos Escravos da Virgem Maria e Porta Fidei ${ }^{15}$ e outros grupos cristãos. Estes grupos defendem o celibato até o casamento e a submissão da mulher ao homem.

Além dos grupos, participaram do protesto, padres católicos e o próprio Arcebispo do Recife, Dom Fernando Saburido divulgou um vídeo de repúdio ao aborto, dizendo: "Quero contestar inteiramente essa decisão. A igreja defende a vida em qualquer circunstância. Essa criança tem, sim, condições de sobreviver. Precisamos salvar a vida da mãe e do filho ${ }^{16}$ ".

\footnotetext{
14 https://www.cnbb.org.br/elas-deverao-aprender-de-novo/.

$15 \mathrm{https}$ //marcozero.org/as-comunidades-catolicas-por-tras-do-protesto-contra-aborto-no-recife/.

${ }^{16} \mathrm{https}: / /$ www.youtube.com/watch?v=2IZephzCmSA.
} 
O protesto para evitar que a menina estuprada fizesse o aborto legal e seguro ocorreu em frente ao hospital público, onde foi realizado o procedimento. Na plataforma Youtube ${ }^{17}$, há videos mostrando como os opositores do aborto bloquearam a entrada da clínica e tentaram impedir a passagem dos médicos responsáveis pelo procedimento. O bloqueio só pôde ser quebrado com a intervenção da polícia. A menina também teve que entrar no hospital sob proteção policial, onde finalmente fez o procedimento. A menina de dez anos foi ofendida pelos religiosos, que a chamaram de "assassina" 18.

O caso se tornou público depois que a ministra da Mulher, Família e Direitos Humanos, Damares Alves ${ }^{19}$, que se autodenominou como "terrivelmente cristã" 20 , lamentou a decisão judicial nas redes sociais. Como resultado, outros políticos religiosos e apoiadores do presidente Jair Bolsonaro pressionaram o judiciário e a família da menina, chegando mesmo a divulgarem o nome da criança e do hospital onde se fez o aborto.

Observa-se ainda, o pânico moral instalado nesses setores que nos últimos anos ao fazer críticas e censurar exposições de arte, shows e performances artísticas, colocando-as na lista daquilo que consideram desvio do dinheiro público para o financiamento da pedofilia. Em 2017, ficaram nacionalmente conhecidos os casos da Exposição "Queer Museu: Cartografias da diferença na arte brasileira" ${ }^{21}$ em Porto Alegre; da performance do artista Wagner Schwartz ${ }^{22}$ no Museu de Arte Moderna em São Paulo e os protestos e agressões dirigidas à filósofa norte-americana Judith Butler, na ocasião da realização de seminário sobre democracia em São Paulo. Após a polêmica, a exposição “Queer Museu, foi imediatamente cancelada pelo Banco Santander, financiador do projeto ${ }^{23}$. Em Mato Grosso do Sul, também em 2017, o quadro "Pedofilia" da artista plástica Alessandra Cunha foi apreendido pela Polícia Civil. A ação foi resultado de um boletim de ocorrência aberto pelos deputados estaduais ligados a bancada religiosa, Paulo Siufi (MDB), médico católico e militante contra o aborto, Herculano Borges (Solidariedade) e Coronel David (PSC) na Depca (Delegacia Especializada de Proteção à Criança e ao Adolescente), logo após uma sessão parlamentar na qual o tema da mostra cancelada no Rio Grande do Sul teria sido duramente criticada pelo deputado - pastor Lidio Lopes. A artista se defendeu dizendo que o assunto pedofilia é um tabu que sequer se pode tocar no nome. A obra pretendia denunciar a existência da pedofilia, mas foi apreendida sob a acusação de incitá-la e sendo considerada pelo delegado que fez a apreensão como uma obra que "feria a moral e bons costumes" 24 .

Ainda nesse contexto, Bento (2019) chama a atenção para a votação da admissibilidade do impedimento da exPresidenta Dilma Rousseff, que aconteceu no dia 17 de abril de 2016, na Câmara dos Deputados. Para a autora é como se a “Marcha da Família com Deus pela Liberdade” estivesse acontecendo outra vez. Não nas ruas, como na sua primeira edição em 1964, assistimos, em grande estilo, à consolidação de uma agenda política da elite moral deste país. Grande estilo porque tudo se deu nos marcos do Estado de Direito, na Casa do povo, ungidos pelo voto popular. Em 1964, se pedia o Golpe para livrar as famílias da ameaça comunista. Em 2016, a votação do impedimento foi em nome de uma agenda moral da defesa da família.

\footnotetext{
17: https://www.youtube.com/watch?v=Mo9qIkIzxuw.

${ }^{18} \mathrm{https}: / / \mathrm{www}$.youtube.com/watch?v=X5hKgWECJss.

${ }^{19} \mathrm{https}: / /$ docs.google.com/document/d/1SGTgISv6acp4AeBr3jV2pDm70RnRvJaI/edit.

${ }^{20} \mathrm{https} / / / \mathrm{g} 1 . g l o b o . c o m / p o l i t i c a / n o t i c i a / 2019 / 01 / 02 /$ estado-e-laico-mas-esta-ministra-e-terrivelmente-crista-diz-damares-ao-assumir-direitoshumanos.ghtml.

${ }^{21}$ https://brasil.elpais.com/brasil/2017/09/11/politica/1505164425_555164.html.

22 : https://www.rfi.fr/br/brasil/20180416-apos-ser-acusado-de-pedofilia-no-brasil-wagner-schwartz-apresenta-la-bete-em-paris.

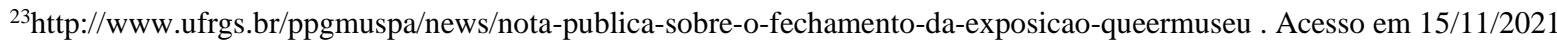

${ }^{24} \mathrm{https}$ ///veja.abril.com.br/entretenimento/obra-quedenuncia-pedofilia-e-tirada-de-museu-acusada-de-incita-la/.
} 
Quem escutar estas declarações daqui a alguns anos, certamente se perguntará: o Projeto que estava sendo votado era para salvar a família? Não era. E era. Não era porque a discussão deveria ser em torno do impedimento ou não da presidenta da República. E era porque o debate sobre moralidades ocupou um lugar importante nos embates que se travaram em todas as instâncias do parlamento (nas Comissões, no Plenário). Em algum momento, os setores conservadores (prefiro utilizar "conservadores" a "evangélicos”, porque a adesão a um ideário tradicional de família não foi prerrogativa exclusiva dos evangélicos e/ou e outras religiões). (Bento, 2019, p. 12)

Bento ressalta que o resultado favorável ao impedimento da Ex-Presidente tem como ponto de unidade o acerto de contas com os defensores dos direitos humanos, feministas e LGBTQIA+. As e os parlamentares que disseram sim ao impedimento estavam dizendo não ao projeto político-partidário do governo do Partido dos Trabalhadores, que incluía políticas de inclusão de mulheres e minorias sexuais. A votação representou acima de tudo, o retorno do país/reino de Deus sem a presença daquilo que os religiosos consideram como seres abjetos.

A disputa pelo controle da hegemonia cultural continuou nos anos seguintes, e pautou em grande parte, as eleições presidenciais de 2018, Jair Bolsonaro, candidato ligados aos movimentos conservadores e religiosos acusou o então candidato petista, Fernando Haddad de ser favorável à "ideologia de gênero, e que se o mesmo fosse eleito iria distribuir em todas as escolas o "kit gay", já identificado anteriormente. Para Bento (2019), o "kit-gay" tornou-se significante à medida que pessoas de diferentes segmentos sociais começaram a associá-lo ao aumento de homossexuais no país.

Uma senhora que me afirmava que não iria votar no candidato "do Lula" porque o PT distribuiu o "kit-gay" nas escolas. Contra argumentei (acessando sites na internet) afirmando que o "kit-gay" não existiu. A senhora não se deu por vencida e me perguntou: "ora, se não teve este kit-gay, como têm tanto homossexual hoje em dia? (Bento, 2019, p. 16)

Esta pauta moral foi bastante comum durante toda a campanha. Por mais que se alertasse para o fato de ser uma fake news, às pessoas (seja da classe média ou da periferia) viam concretamente "o que era irrefutável": tem mais homossexuais hoje do que antes do PT. E a relação analítica é direta: tem mais LGBT hoje por causa do PT’. (Bento, 2019, p. 16).

Todas essas questões em torno da discussão sobre (ideologia de) gênero e sexualidade são algumas das narrativas sobre as tensões produzidas no país e nas instituições sociais que nos permitem reconhecer esta problemática como um dos fenômenos culturais emblemáticos de nossa época.

Assim, ideias e conceitos serão aqui discutidos com a finalidade de esboçar hipóteses que dêem conta de se entender a força e centralidade destas questões, marcadas, sobretudo, por uma disputa política e moral para o controle cultural da época atual. Assim por que temas como a descriminilização ou não do aborto é discutido de forma tão apaixonada? Por que o casamento homoafetivo; o direito à adoção por casais do mesmo sexo; o tema dos direitos humanos no século XXI aparece para certos grupos como uma abominação e que o Estado não deve amparar essa configuração familiar? A partir de que lógicas biopolíticas e bioculturais emanam as defesas exaltadas desses discursos? Como esses discursos criam a política dos corpos, do desejo, da reprodução e do afeto de corpos dissidentes e constantemente controlados e que não se deixam controlar? Como pensar em sujeitos diferenciados, com vidas cotidianas regidas por valores também diferenciados, que são baseados em premissas fundamentais de comunidades ideológicas imaginadas, que apesar de compartilhar um território nacional não parecem se pautar pela diversidade e diferença? Na atualidade, tanto no Brasil como em outras partes do mundo, os sentidos atribuídos ao gênero e a diversidade sexual integram propostas societais distintas, que nomeiam as coisas, as interpretações e as compreendem de maneiras diferenciadas. Representam olhares sociopolíticos sustentados por premissas morais e códigos jurídicos diferentes, com padrões institucionais de forma e conteúdos bastante distintos. Trata-se de pensamentos diferentes na disputa pela hegemonia da interpretação cultural. São temas emblemáticos da contenda contemporânea por cidadania em tempos de desajuste, instabilidade e incertezas, tempos que muitos consideram como de transição entre as épocas. 
Hunter (1991) usa o conceito de guerra cultural em seu livro de mesmo nome, para apresentar a tese que em países como os Estados Unidos, a cultura pública experimenta um notório realinhamento e polarização que cria tensões e conflitos emanados de propostas sobre o sentido da diferença, da diversidade e da liberdade. São representações distintas do que seja a identidade nacional, do que é ser norte-americano, centradas primordialmente no corpo reprodutor da mulher e no desejo, porém abarcando outros temas que se rivalizam como os sistemas de compreensão moral, de valores e crenças que constituem identidades coletivas, objetivos existenciais, formas de coesão social e imaginários sociais díspares. Segundo o autor, estes ideais morais estabelecem disputas sobre o ordenamento social, as leis, a administração, com base muitas vezes em cosmovisões religiosas já superadas na esfera pública, mas que interrogam a democracia atual. (p. 42-43).

É interessante indicar que essa agudização das tensões em torno a igualdade substantiva e a cidadania efetiva desses novos sujeitos sexuais e a autonomia e poder de decisão que as mulheres detém sobre seus corpos se inserem em um contexto histórico particular. Esse contexto em que a reconfiguração do tempo e do espaço é produzida por uma intensa inovação tecnológica e reorganização estrutural do neoliberalismo globalizado destruindo a solidez das instituições modernas, tornandoas desajustadas e disfuncionais.

Nesse aspecto, Touraine (1999) anota que na conjuntura atual, a desinstitucionalização se articula e potencializa a dessocialização, manifestando variações significativas de reprodução das normas institucionais estabelecidas devido as expressões de resistência e a processos de reacomodação existentes. Por isso, a sensação de normalidade de eras anteriores é substituída por uma atmosfera existencial permeada pela irregularidade, imprevisibilidade e improvisação. (p. 33-35).

Por seu lado, Beck (2018) se refere a organização capitalista contemporânea como um modelo de produção industrial sem sociedade industrial, caracterizando a sociedade industrial como um sistema congruente de produção, política e cultural: “Um modelo de vida em que os papéis sexuais, a unidade familiar e classes formam parte de uma mesma cadeia” (Beck, p. 206).

Certamente, como aponta Giddens (2012), a família é um local para apresentar a disputa entre a tradição e a modernidade, sendo por sua vez, fonte de segurança e da sociabilidade em outros tempos, perdeu como nenhuma outra instituição, suas raízes fincadas no passado. Se na atualidade, como afirma Giddens, a vida privada é o terreno de uma "revolução global" que incide em como pensamos e em como nos conectamos com os demais campos da sexualidade, com as relações amorosas, o casamento e a família, não é de estranhar a intensidade emocional da contenda que se estabelece. Enfim, a defasagem entre a velocidade das transformações e a vida cotidiana, juntamente com a precariedade generalizada das formas institucionais abre o campo para as disputas pela hegemonia dos significados culturais. Aliado às mudanças tecnológicas, estruturais e cotidianas em processo, o debate em torno a cidadania e o reconhecimento dos sujeitos sexuais como mulheres e LGBTQIA+ sugerem que mais que uma época de crise intensa e constantes mudanças, estamos adentrando a uma transição entre épocas .

Os discursos sobre a igualdade de gênero e o reconhecimento dos corpos dissidentes e transgressores de LBGTQIA+ irromperam em grande parte do mundo ocidental - sobretudo nos países centrais do capitalismo- durante a segunda metade do século XX, quando novos atores coletivos interrogaram crenças profundamente enraizadas no imaginário social e no habitus individual $^{25}$. Essas crenças pensavam a maternidade como uma essência natural entre as mulheres e a heterossexualidade como a única orientação sexual aceitável. Um crescente acúmulo de teorias sobre a condição da desigualdade feminina,

\footnotetext{
25 Bourdieu (1996:29) apresenta a categoria habitus para referir-se ao processo de assimilação dos mandatos normativos sociais nas profundidades psíquicas e corporais dos indivíduos. O habitus encerra uma dialética entre o estruturado - a normatividade existente - e o estruturante - a normatividade reproduzida - funcionando como um dispositivo de produção e reprodução das relações sociais assimétricas. Falando especificamente de gênero, o autor explica o habitus sexuado e sexuante, que somatizado nos próprios tecidos reflexos do corpo das pessoas e normatiza na psique a relação de dominação entre homens e mulheres, forjando, assim, a suas respectivas identidades de maneira que pareçam binárias. sistema e disciplina.
} 
subordinação, marginalização e exclusão identificou essas dimensões da existência- quer dizer, a reprodução e a sexualidade como campos marcados pelo poder, altamente normalizados, todavia suscetíveis de transformações históricas.

Conceber o corpo como fonte de cidadania, com autonomia, capacidade e direito de decidir sobre seus processos, desejos e pulsões, contribuiu para desnaturalizar a visão habitual da modernidade industrial - intimamente vinculada ao imaginário cristão- do corpo biológico, ahistórico e sem influência cultural, cuja natureza, no caso das mulheres, é de produtora essencial e incondicional a partir de outra natureza presumida: a heterossexualidade. Assim, não é de estranhar que a figura da família nuclear, de profunda orientação patriarcal, seja o referente simbólico que aglutina e inspira por meio das ortodoxias religiosas os movimentos conservadores projetos políticos-partidários no Brasil e em outras partes.

Nesse sentido, nas modernas sociedades industriais, a criação de uma esfera privada de âmbito familiar é indissociável da introdução dos mecanismos de controle dos impulsos e dos afetos na vida pública. A auto-disciplina afetiva e corporal é a condição do engajamento dos sujeitos na ordem social, diria Foucault (1987), para quem a submissão voluntária é o braço subjetivo do poder. O auto-policiamento permanente é o preço a ser pago pela vida moderna, sobretudo nas cidades. No século XVIII o corpo é descoberto como uma fonte inesgotável de poder, enquanto máquina, sistema e disciplina. É simultaneamente dócil e frágil, algo possível de manipular e facilmente adestrável, enfim, suscetível de dominação. Este poder disciplinar não reduzirá sua aplicabilidade apenas ao corpo do indivíduo, mas dirigiu-se também aos corpos sociais sendo responsável por hierarquizar e classificar os sujeitos no campo social. Cada relação social implica assim em um espaço de luta devido aos diferentes tipos de ligação e interesses que um mesmo indivíduo pode manter com os demais por sua posição e reconhecimento. $\mathrm{O}$ argumento foucaultiano no que concerne ao fenômeno do poder, entende sua atuação no corpo social com suas técnicas e estratégias, exercida não somente em aspectos negativos de censura e proibição, mas também em aspectos positivos sobre os corpos, prazeres e saberes. Afinal isso explicaria em grande parte como esse poder se estabeleceu e se perpetuou ao longo da modernidade.

Butler (2015) vincula a discussão de corpo e gênero com a noção de vidas precárias, vidas contemporâneas potencialmente indesejáveis que não contam como o mesmo reconhecimento social das vidas que se valem a pena viver: vidas descarregadas de cidadania, carente de direitos plenos que a que a noção de cidadania presente no projeto moderno, prometeu proteger. As vidas precárias se relacionam intimamente com a performatividade de gênero por não se ajustarem de forma plena com as expectativas habituais que socioculturalmente modelam as identidades sexuais. Quer dizer, com manifestações e margens diferenciais, as vidas precárias representam expressões não plenamente inteligíveis no contexto dos mandatos normativos de gênero, que são estabelecidos e institucionalizados de maneira binária e que, ademais, são reproduzidos de maneira fiel através da performatividade. A autora enfatiza o papel de performatividade na reprodução do gênero, invocando não somente as normas regulatórias que definem os protótipos identitários, mas também as pautas do desejo e a lógica de poder. Juntas estas facetas são percebidas no imaginário social como uma verdade inerente na natureza manifesta, uma essência inata. Porém, a repetição performativa não é um exercício carente de agência.

Para Butler, "a reprodução do gênero é sempre uma negociação de poder", (2007, p. 156) assinalando que precisamente através da replicação das normas de gênero se evidenciam as margens de cumprimento ou não das mesmas. E isto “(...) abre a possibilidade de uma reelaboração da realidade de gênero por meio de novas formas “. (2007, p. 156). Nesta perspectiva, o gênero não é algo fixo e pré-estabelecido, e sim que está em constante tensão através do filtro da performatividade individual das normas de gênero em contextos socioculturais e momentos históricos específicos. Em outras palavras, a performatividade reforça ou questiona a normatividade mediante a aceitação ou a transgressão dos sujeitos, dos discursos e os atos em termos particulares. Assim, a irrupção e consolidação de novos atores e discursos sobre o gênero e a 
sexualidade e a reação dos grupos religiosos são exemplos do momento histórico de fratura e transição, mostrando assim, a dimensão emblemática da disputa pela hegemonia normativa dessa época de incertezas.

Portanto, estas não só são instâncias de poder, e Butler (2007) define a performatividade de gênero como a repetição individual minuciosa e constante de expressões físicas, atitudes e manifestações emocionais associadas às identidades sexuais de homens e mulheres, sempre antecedida e informada por uma normatividade cultural de gênero - usualmente binária - que forma parte do imaginário coletivo das sociedades. "Não só refletem noções mais amplas de poder, mas que são uma maneira através do qual se opera o poder” (Butler, 2007, p. 154). Desta forma, mediante as intervenções e controles reguladores da biopolítica, em cada etapa histórica da formação socioeconômica e cultural se institucionalizam - e se disputam - as políticas sexuais traçando uma linha divisória entre as vidas socialmente reconhecíveis e as vidas precárias. E são estas últimas que estão expostas ao rechaço e a exclusão, ao dano físico, emocional e psíquico, a violência da sociedade, do Estado e por muitas vezes, até a morte.

Assim, os debates passionais em torno aos valores e os sentidos culturais, envolvendo as questões de gênero e a diversidade sexual no Brasil durante os últimos anos, estampam uma espécie de geopolítica corporal no mapa nacional, que divide o país em falas que limitam o diálogo entre os defensores da pluridiversidade de um lado e os religiosos de outro. Tal geopolítica concede possibilidades e proibições distintas aos corpos segundo a posição em que se encontram.

Para mulheres e LGBTQIA+, a institucionalização internacional e nacional dos direitos sexuais e reprodutivos durante a década de 1990 representa um dos dispositivos mais importantes para alcançar a cidadania plena. O reconhecimento do direito de cada pessoa ao prazer, à saúde sexual e reprodutiva, à liberdade de consciência e a decisão sobre estes aspectos fundamentais da vida, define novos campos de subjetivação e cidadania.

O próprio termo direitos reprodutivos salta para o cenário institucional global pela primeira vez no Tribunal Internacional do Encontro sobre Direitos Reprodutivos, em Amsterdã, em 1984, como uma confirmação da crescente aceitação do pensamento feminista sobre autonomia reprodutiva e liberdade sexual (Correia; Avila, 2003, p. 19). Sua posterior concretização no Plano de Ação da Conferência das Nações Unidas para a Década da Mulher, realizada em Nairóbi (ONU, 1985), e na Plataforma de Ação da Quarta Conferência da Mulher em Pequim (ONU, 1995), constituiu a pedra angular de um novo discurso que define os componentes, condições, ações e orientações das políticas públicas de bem-estar sexual e reprodutivo de indivíduos e casais (Corrêa; Ávila, 2003, p. 22-23).

A Conferência Internacional sobre População e Desenvolvimento no Cairo (ONU, 1994) e a Conferência Mundial sobre Direitos Humanos em Viena (ONU, 1993), definiram a saúde sexual como um direito humano para ambos o sexos e ressaltaram sua importância como uma vertente fundamental do ser humano, intimamente ligada ao direito à saúde integral e deslocada do discurso - até então hegemônico - da regra da moralidade. Isso abre a possibilidade de perceber as diferentes expressões da diversidade sexual como manifestações humanas reconhecíveis que - seguindo Butler - são a condição para a sujeição social como um corpo que importa, uma vida que merece ser vivida (Butler, 2015, p. 322).

Também inseridos no conceito de saúde integral, os direitos reprodutivos referem-se a dois aspectos fundamentais da subjetivação e cidadania da mulher: o direito de tomar decisões informadas sobre o exercício de sua capacidade reprodutiva e o acesso a recursos que o garantam a realização dessas decisões em condições ideais. Pelo mesmo motivo, especialistas consideram que os direitos reprodutivos e sexuais articulam o exercício das liberdades pessoais com o cumprimento dos direitos sociais (Costa, 2009; p. 1078), articulando o privado e o público e o pessoal e o político. em uma dialética que valoriza a qualidade de vida.

A promoção destes direitos a nível global, nacional e local tem significado, para os seus apoiadores, o enriquecimento e expansão dos conceitos de igualdade, justiça e cidadania; mas para a igreja, eles representam a violação da vontade divina, 
dos textos sagrados e das ordens eclesiásticas. Assim, duas interpretações radicalmente diferentes dos direitos humanos são incorporadas, com avaliação e ordenação diferenciadas, que são baseadas em fontes de legitimidade igualmente diferentes. A primeira identifica a evolução histórica, o surgimento de novos sujeitos e a vontade popular como motores do desenvolvimento desses direitos, caracterizando-os como inalienáveis, imprescritíveis e indivisíveis, e reconhecendo-os como produtos da história humana. Desse olhar, não há avaliação hierárquica desses direitos, mas com igual valor todos eles compõem um conjunto de diretrizes ético-morais, que em sua totalidade representam uma proposta paradigmática laica de cidadania global. Assim, o direito à saúde sexual e reprodutiva terá o mesmo valor que o direito à vida, ao trabalho, à liberdade de imprensa, à própria cultura ou a um ambiente saudável.

Pela interpretação contida, a representação divina é aquela que concede os direitos humanos às pessoas. É a consciência onipresente que dá sentido social, elevando em primeiro lugar o direito à vida - por sua relação presumida com a intenção sagrada de administrar essa vida - e enfatizando prioritariamente e em ordem hierárquica os direitos ancorados nos textos sagrados e nos ensinamentos religiosos. Essa visão dos direitos humanos reproduz as premissas, diretrizes e valores eclesiais em outra totalidade paradigmática global pautada por uma hermenêutica religiosa.

Por isso, a atual disputa pela hegemonia dos sentidos culturais não envolve apenas a interpretação dos direitos humanos, mas também se refere à própria natureza do Estado e sua relação com a religião, algo central na definição e funcionamento do Estado moderno.

Nesse sentido, hoje, ambos - os direitos humanos e o Estado - também se tornam campos de intensa disputa. Envolvidos nas tensões pelo controle do corpo da mulher, pela personificação do embrião e pelo reconhecimento social ou não da diversidade dos sujeitos sexuais, abordam-se duas visões de Estado e de direitos: uma amparada pelo paradigma laico e outra ancorada à lente religiosa. A primeira restringe a herança dos cânones religiosos no trabalho estatal, garante reciprocamente a autonomia e a liberdade religiosa e o exercício da liberdade de consciência, e assenta na validação do sentimento popular como autoridade máxima e fonte de acumulação de direitos. A segunda visão entende os textos sagrados como representações fiéis da palavra e intenção divinas, entendendo essas fontes -palavra e intenção de Deus- como de legitimidade universal, a-histórica, eterna e anterior à ordem social. Esta leitura é baseada em uma ordem hierárquica de uma divindade todo-poderosa que inclui tudo e todos sob a interpretação, controle e punição de especialistas e autoridades religiosas, e sua essência autoritária é replicada em instituições sociais fundamentais como a família.

Portanto, no século XXI, embora a disputa entre o secular e o religioso seja mais uma vez colocada na primeira página da disputa política, agora na nova rodada da globalização capitalista a área de disputa é outra. Em contraste com os primeiros séculos da modernidade quando as estruturas feudo-eclesiais e os abalos secundários foram combatidos, lutando pelas terras, propriedades e poderes políticos da Igreja na esfera pública, atualmente, em meio ao colapso do modelo de vida industrial que articulou o papéis dos sexos, da unidade familiar e das classes em um conjunto congruente, a disputa opera diretamente na intimidade dos corpos, no desejo sexual e na capacidade reprodutiva, espaços nos quais a rivalidade para delimitar o controle-autonomia simboliza uma nova luta pelas margens da influência religiosa no trabalho público e político e, portanto, na própria definição do Estado. Isso, por sua vez, afeta a formulação - e a institucionalização - do conteúdo social, valores sociais, normatividade, crenças, imaginações coletivas, identidades e ações permitidas.

Da mesma forma, contribui centralmente para a definição de quem são os atores reconhecíveis, quais vidas são precárias, que tipo de ação é permitida e quais têm margem de barganha para graus menores ou maiores de liberdade individual e coletiva. Isso, por sua vez, afeta a formulação - e a institucionalização - do conteúdo social, valores sociais, normatividade, crenças, imaginações coletivas, identidades e ações permitidas. 


\section{Considerações Finais}

Os apaixonados debates e legislações sobre aborto e as questões de gênero nos últimos anos, marcam uma espécie de geopolítica do corpo no mapa nacional, que divide a população em faixas bem definidas de cosmopolitas multiversos, por um lado, e conservadores e religiosos, por outro. Tal geopolítica concede possibilidades e proibições diferentes aos corpos de mulheres e LGBTs, os direitos reprodutivos e sexuais são interpretados e aplicados de forma diversa nas diferentes entidades do país, forjando cartografias corporais específicas que não se diferenciam apenas no grau de cidadania mas também na igualdade de direitos,

Além disso, a geopolítica do corpo agencia diferentes biopolíticas, tornando visível na esfera pública brasileira a demarcação de diferentes propostas de sociedade que simbolizam os fatos e caracterizam a realidade social a partir de filtros culturais díspares. São, então, duas propostas sociais distintas, com visões diferenciadas da moral, dos valores, dos sujeitos reconhecíveis, da interpretação dos direitos humanos, da relação entre Estado e religião e da própria natureza do projeto de Estado-Nação. São visões sociopolíticas concorrentes que emergem das tensões e oportunidades da atual conjuntura histórica de intensas mudanças tecnológicas e estruturais: de institucionalidade, dessocialização, instabilidade, incerteza, riscos e mudanças na concepção que marcam a época atual.

De fato, é nos interstícios da disfuncionalidade institucional dessa transição que os discursos sociais em confronto disputam a hegemonia da interpretação cultural. No caso das questões emblemáticas do aborto, da (s) sexualidade (s) e o gênero o que se discute é a natureza da família. Posições diferenciadas em torno de ambas as questões (re) definem a composição, o parentesco, a divisão sexual do trabalho, a organização e -especialmente- as relações de poder desta referida unidade básica da sociedade. É a própria definição de família, que por sua vez afeta o caráter do Estado e outras relações sociais. E é por isso que a interpretação do aborto, da sexualidade e do gênero é contestada de forma tão apaixonada e se tornou central na disputa por significados culturais no que se pode chamar de modernidade colapsada.

\section{Referências}

Beck, U. (2018) A metamorfose do mundo: Novos conceitos para uma nova realidade. Rio de Janeiro: Zahar Editor.

Bento, B. (2019) Uma nova agenda moral? In: A. M. Gomes, A. F. dos Reis, V. S. Veiga (eds) Sexualidades, gêneros e conservadorismos. campo grande: life. 7-21.

Bento (Papa) XVI. (2005). Carta Encíclica Deus caritas est. 25 de dezembro de 2005. https://www.vatican.va/content/benedict-

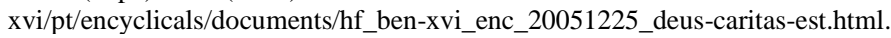

Bento (Papa) XVI. (2012). Discurso do papa Bento XVI à Cúria Romana na apresentação dos votos natalícios, 21/12/2012. http://www.vatican.va/content/benedict-xvi/pt/speeches/2012/december/documents/hf_ben-xvi_spe_20121221_auguri-curia.html.

Bourdieu, P. (2010) A dominação masculina. Rio de Janeiro: Bertrand Brasil.

Butler, J. (2015) Quadros de guerra: Quando a vida é passível de luto? Rio de Janeiro: Civilização Brasileira.

Butler, J, (2007). Corpos que pesam: sobre os limites discursivos do sexo. In: G. L. Louro. O Corpo Educado: Pedagogias da sexualidade. Belo Horizonte: Autêntica, 149-167.

Conferência Nacional dos Bispos do Brasil. (2021). Elas deverão aprender de novo? Website da CNBB: https://www.cnbb.org.br/elas-deverao-aprender-denovo/

Corrêa, S; Ávila, M. B. (2003) Direitos sexuais e reprodutivos -pauta global e percursos brasileiros. in: E. Berquó, (org) Sexo \& Vida: panorama da saúde reprodutiva no Brasil. Campinas: Edunicamp,

Dumoulié, C. (2007). Os significados do excesso. Rio de Janeiro: Tempo Brasileiro.

Foucault, M. Vigiar e punir: nascimento da prisão. (1987). Petrópolis: Vozes, 1987.

Francisco (Papa). (2015). Discurso do Santo Padre em encontro com os jovens em Manila, 15/01/2015.

https://www.vatican.va/content/francesco/pt/speeches/2015/january/documents/papa-francesco_20150116_srilanka-filippine-incontro-famiglie.html 
Research, Society and Development, v. 10, n. 16, e240101623590, 2021

(CC BY 4.0) | ISSN 2525-3409 | DOI: http://dx.doi.org/10.33448/rsd-v10i16.23590

Francisco (Papa). 2017. (Apud) BATTISTI, A. Ideologia de gênero: http://arquidiocesedemaringa.org.br/palavradobispo/126/ideologia-de-genero..

Giddens, A. (2012). O mundo na era da globalização. Lisboa: Presença.

Hunter, J. D. (1991). Culture Wars. The Struggle to Define America. New York: BasicBooks.

Junqueira, R. D. (2017). "Ideologia de gênero": um dispositivo retórico de uma ofensiva antifeminista. In: A. DIAS, (ed). Gênero e sexualidades: entre invenções e desarticulações. Aracaju: Editora IFS. p. 47-61.

Laclau, E. (2013). A Razão Populista. São Paulo: Três Estrelas.

Mariano, R. (2013). Mudanças no campo religioso brasiliero no censo de 2010. Debates do NER, Porto Alegre, ano 14, n. 24 , jul./dez. p. 119-137. https://seer.ufrgs.br/debatesdoner/article/view/43696/0

Organização das Nações Unidas. (1994) Relatório da Conferência Internacional sobre população e desenvolvimento, Cairo 1994.

https://brazil.unfpa.org/sites/default/files/pub-pdf/relatorio-cairo.pdf.

Organização das Nações Unidas. (1993) Declaração e Programa de Ação de Viena: Conferência Mundial sobre Direitos Humanos.

https://www.oas.org/dil/port/.

Ratzinger, Joseph (Cardeal). (2004). Carta aos bispos da igreja católica sobre a colaboração do homem e da mulher na igreja e no mundo em 31 de maio de 2004. https://www.vatican.va/roman_curia/congregations/cfaith/documents/rc_con_cfaith_doc_20040731_collaboration_po.html.

Rosado, M. J. (2018). Quando a natureza não é mais uma ordem: Os desafios do feminismo à religião. In: A. M. GOMES, A. F. dos Reis, V. S. VEIGA. (eds). Diálogos sobre gênero e sexualidade. Campo Grande: Life. 10-28.

Souza Junior, Paulo Roberto. (2019). A influência do neoconservadorismo nos estudos de gênero no Brasil. Revista de Gênero, Sexualidade e Direito. v5, n2, Belém, jul-dez de 2019, pp. 55-73.

Touraine, A. (1999). Poderemos viver juntos? Iguais e diferentes. Petrópolis: Vozes.

Trevijano, P. (2018)! Que no te engañen!, hombre o mujer. Todo sobre la ideología de género. http://capacitate.frentenacional.mx/wpcontent/upoads/2019/06/Que-no-te-enga\%C3\%B1e-hombre-o-mujer-Pedro-Trevijano.pdf.

Vaggione, J. M. (2017). La Iglesia Católica frente a la política sexual: la configuración de una ciudadanía religiosa. Campinas: Cadernos Pagu. Unicamp. N 50. (n. p.). https://www.scielo.br/pdf/cpa/n50/1809-4449-cpa-18094449201700500.002.pdf DOI: https://doi.org/10.1590/18094449201700500002 